\title{
Case Report: Large Cervical Mass
}

\author{
Sushila B Ladumor* \\ Consultant Radiologist, Weil Cornel Medical College, Qatar
}

Submission: May 23, 2018; Published: June 25, 2018

"Correspondence Address: Sushila B Ladumor, Consultant Radiologist, Hamad Medical Corporation, HGH, Clinical Imaging, P.0. Box 3050, Doha, Qatar, Assistant Professor in Clinical Radiology, Weil Cornel Medical College, Doha, Qatar (WCMC-Q).

Email: drsbladumor@yahoo.com

\section{Abstract}

Cancer of uterine cervix is the third most common gynecologic malignancy, with mean age at onset of 45-55 years [1]. The International Federation of Gynecology and Obstetrics (FIGO) staging system are used mostly for treatment planning but more often for standardization of epidemiologic and treatment results (Table 1) [1]. Imaging plays a key role in diagnosing particularly for staging (deep pelvic invasion, lesion volume and nodal metastasis) as it is poorly assessed by gynecologic examinations. Therefore, magnetic resonance (MR) imaging is now modality of choice for proper evaluation of mass and local staging as well as in selection of therapeutic strategy.

Keywords: Cervical mass; Parametrium; Lymph nodes; Uterine mass; Vaginal invasion; Ultrasound (US); Computerized Tomography (CT); Magnetic Resonance Imaging (MRI); Urinary bladder; Rectum; Hydro nephrosis; Hydro utterer; Neuroendocrine (NE)

\section{Clinical History}

45 years old female with no past medical history, para 2, all normal vaginal delivery. Patient presented to the ED with complaints of abdominal pain, urine retention. She started constipation and difficulty in passing urine since last 2 weeks. Have vaginal discharge with offensive smell.

\section{Clinical Exam (From Cerner)}

Pelvic exam showed a large very offensive cervical mass reaching up to lower vaginal, involving left lateral vaginal wall. DRE: the mass felt pushing the rectum. Left paraetrium involved. Punch biopsy was taken

\section{Histopathology Report from Cerner}

\section{Diagnosis}

i. Cervical biopsy- Extensively necrotic malignant neoplasm with features consistent with small cell neuroendocrine carcinoma.

ii. Wedge resection of right upper and middle lobe nodule.

Metastatic poorly differentiated neuroendocrine carcinoma.

\section{Introduction}

Neuroendocrine neoplasm encompasses a set of tumors that emerge from the diffuse neuroendocrine cell system. These tumors are more commonly discovered in the gastrointestinal tract, pancreas, lung and thymus. Gynaecological NE tumors are uncommon, either as primary or secondary tumors [2]. The most prevalent gynaecological NE tumors are cervical small cell carcinoma and ovarian carcinoids. Invasive cervical cancer is the third most common gynecologic malignancy and a frequent cause of death [3]. There were approximately 13,700 new cases and 4,900 deaths in 1998 with an estimated prevalence of 208,000 [3]. Patient's presentation varies from abnormal vaginal bleeding, vaginal discharge, pelvic pain, and vaginal mass, urinary retention, constipation (as in our patient) in case of large tumor and from local spread of disease or inflammation. $80 \%$ to $90 \%$ of cervical carcinomas are of squamous cell origin, and the tumors can be exophytic or primarily endocervical [3]. From the cervix, tumors spread to the lower uterine segment, vagina, and paracervical space along the broad and uterosacral ligaments as well as involvement of the pericervical tissues includes the bladder, rectum, pelvic lymph nodes, and pelvic side wall [3].

\section{Discussion}

Cervical carcinoma prognosis depends on tumor stage (local and distant metastasis), volume of the primary mass, and histologic grade. There are four stages of disease as defined by the staging system of the International Federation of Gynecology and Obstetrics (FIGO) (Table 1). Treatment depends on the staging of the tumor. Surgical (radical hysterectomy) and Radiation are the modality of treatment with surgical option 


\section{Cancer Therapy \& Oncology International Journal}

offered for the patient having tumor less than or up-to stage IIA. IIB disease, in stage IIA there is no parametrial involvement, and The main concern in differentiating between stage IIA and stage parametrial involvement seen in stage IIB disease [4].

Table 1: Correlation between FIGO Staging, MR Imaging Staging, and Treatment of Cervical Carcinoma.

\begin{tabular}{|c|c|c|c|}
\hline & FIGO Staging & MR Imaging Staging & Treatment \\
\hline 0 & Carcinoma in situ & Not visible & \\
\hline \multirow[t]{7}{*}{ I } & Confined to cervix & \multirow{3}{*}{ No tumor visible } & Surgery \\
\hline & IA Microscopic & & \\
\hline & IA-I Stromal invasion $<3 \mathrm{~mm}$ & & \\
\hline & IA-2>3mm, 5-mm invasion, 7-mm Width & Small enhancing tumor may be seen & Surgery \\
\hline & IB Clinically visible (>5mm) & $\begin{array}{c}\text { Tumor visible, intact stromal ring surrounding } \\
\text { tumor }\end{array}$ & Surgery \\
\hline & IB- $1<4 \mathrm{~cm}$ & $\ldots$ & Surgery \\
\hline & IB- $2>4 \mathrm{~cm}$ & $\ldots$. & Radiation therapy \\
\hline \multirow[t]{3}{*}{ II } & $\begin{array}{l}\text { Extends beyond uterus but not to pelvic wall } \\
\text { or lower one-third of vagina }\end{array}$ & \multirow{2}{*}{$\begin{array}{l}\text { Disruption of low signal-intensity vaginal } \\
\text { wall(upper two-thirds) }\end{array}$} & \\
\hline & $\begin{array}{l}\text { IIA Vaginal extension, no parametrial } \\
\text { invasion }\end{array}$ & & $\begin{array}{l}\text { Surgery }(\text { if }<4 \mathrm{~cm} \text { ), radiation } \\
\text { therapy (if }>4 \mathrm{~cm} \text { ) }\end{array}$ \\
\hline & IIB Parametrial invasion & $\begin{array}{l}\text { Complete disruption of stromal ring with tumor } \\
\text { extending into the parametrium }\end{array}$ & Radiation therapy \\
\hline \multirow[t]{3}{*}{ III } & $\begin{array}{l}\text { Extension to lower one-third of vagina or } \\
\text { pelvic wall invasion with hydronephrosis }\end{array}$ & \multirow[t]{2}{*}{ Invasion of lower one-third of vagina } & Radiation therapy \\
\hline & IIIA Extension to lower one-third of vagina & & \\
\hline & IIIB Pelvic wall invasion with hydroneprosis & Extension to pelvic muscles or dilated ureter & Radiation therapy \\
\hline \multirow[t]{3}{*}{ IV } & Located outside true pelvis & \multirow{2}{*}{$\begin{array}{l}\text { Loss of low signal intensity in bladder or rectal } \\
\text { wall }\end{array}$} & Radiation therapy \\
\hline & IVA Bladder or rectal mucosa & & \\
\hline & IVB Distal metastasis & $\ldots$ & Radiation therapy \\
\hline
\end{tabular}

It is very important to mention all aspect in detail in MRI urinary bladder and rectum. Any bone involvement. CT chest, report as it plays major role in treatment planning such as tumor abdomen and pelvis or PET CT for distant metastasis. In followvolume, extension to uterus and vagina. Parametrial invasion, up imaging MRI plays key role for evaluation of response of lymph node enlargement, invasion of surrounding structure as treatment as well as in recurrence $[5,6]$.

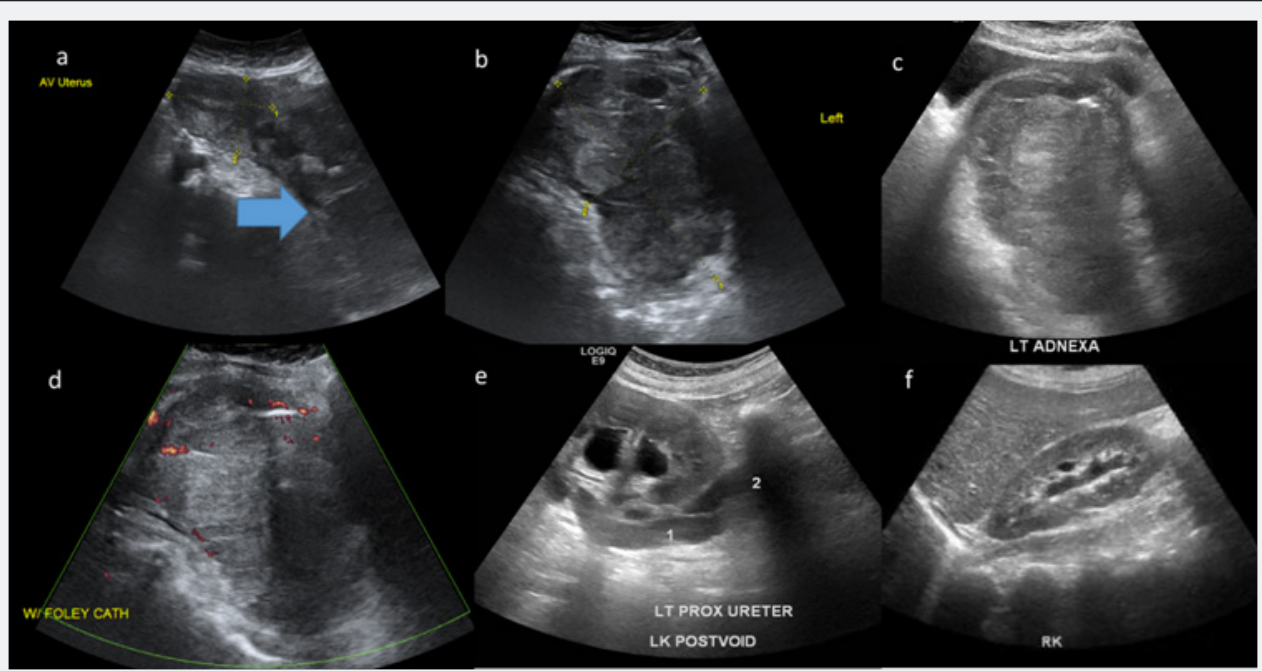

Figure 1: First US requested: Transabdominal US (Transvaginal could not be performed as patient having mass protruding in to vagina): Part of uterus seen in (Image a) with normal endometrial cavity. Large mass seen from utero-cervical region extending down (large arrow in image a) and more towards left adnexal region appears heterogeneous (image a,b,\& c). Color Doppler exam reveal minimal internal vascularity. Patient having catheter in urinary bladder and is collapsed. Left hydro nephrosis and hydro ureter seen indicating invasion of left distal ureter (image e). Minimal right hydro nephrosis with no hydro ureter. No liver lesion (images not shown). 


\section{Cancer Therapy \& Oncology International Journal}

\section{Conclusion}

MR imaging represents the single most effective modality for detection of primary tumor and local spread. CT and MR imaging are equally effective in assessment of nodal involvement. If clinically available, PET scanning improves the specificity and sensitivity of these techniques helps to find out distant metastasis as well as imaging choice of modality in follow-up for response of treatment assessment for tumor as well as distant metastasis. MR imaging also plays key role in follow-up as well as to detect tumor recurrent and observe therapeutic response.

MRI was requested for further work up: Figures 2-4.

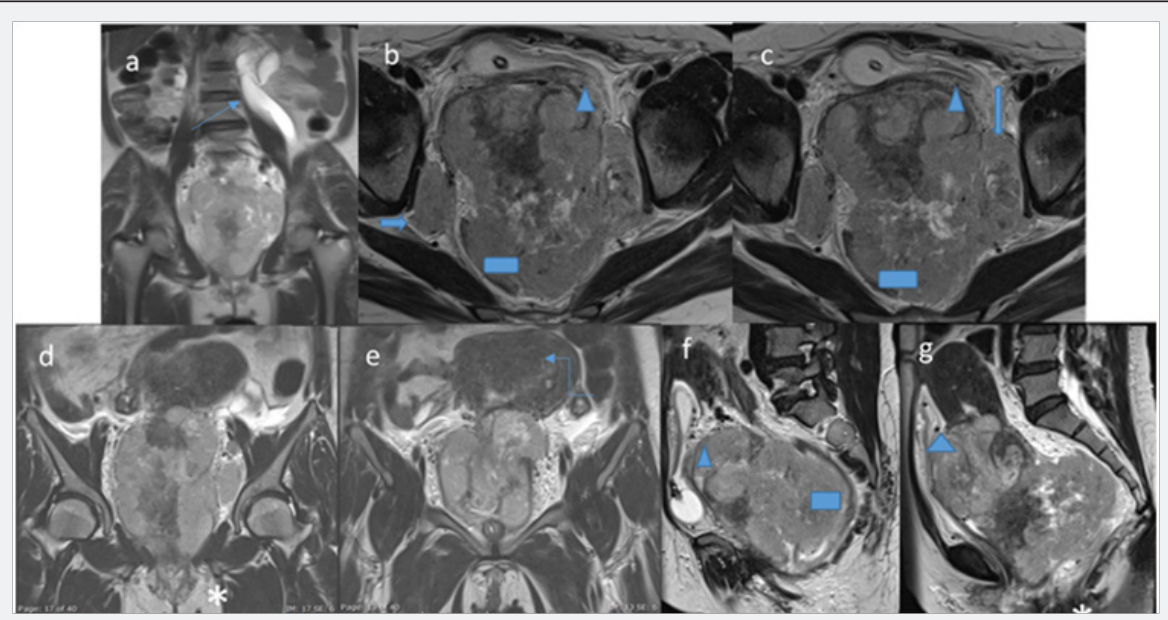

Figure 2: T2 weighted MRI Coronal $(a, d, \&$ e) Axial $(b \& c)$ and sagittal $(f \& g)$ reveals large utero-cervical heterogeneous mass showing intermediate T2 signal extending to lower third of vaginal shown by asterix in(image $d \& \mathrm{~g}$.)Left sided hydro nephrosis and hydro ureter representing mass invading adjacent distal left ureter causing proximal obstructive changes (Thin arrow in image a). Urinary bladder is compressed by large mass with focal loss of normal T2 low signal of urinary bladder wall which appears thick and irregular could be edema or? Focal invasion, shown by triangle in image (b,c,f \& g). Large bilateral iliac lymph nodes shown by thick arrow in image b \&c. Rectum also compressed and displaced towards right side and loss of fat plane and normal T2 low signal of wall indicating invasion shown by rectangle in (image b,c \& f). Incidentally noted sub septate uterus with remarkable widening of junctional zone representing diffuse adenomyosis shown by curved thin arrow in (image e).

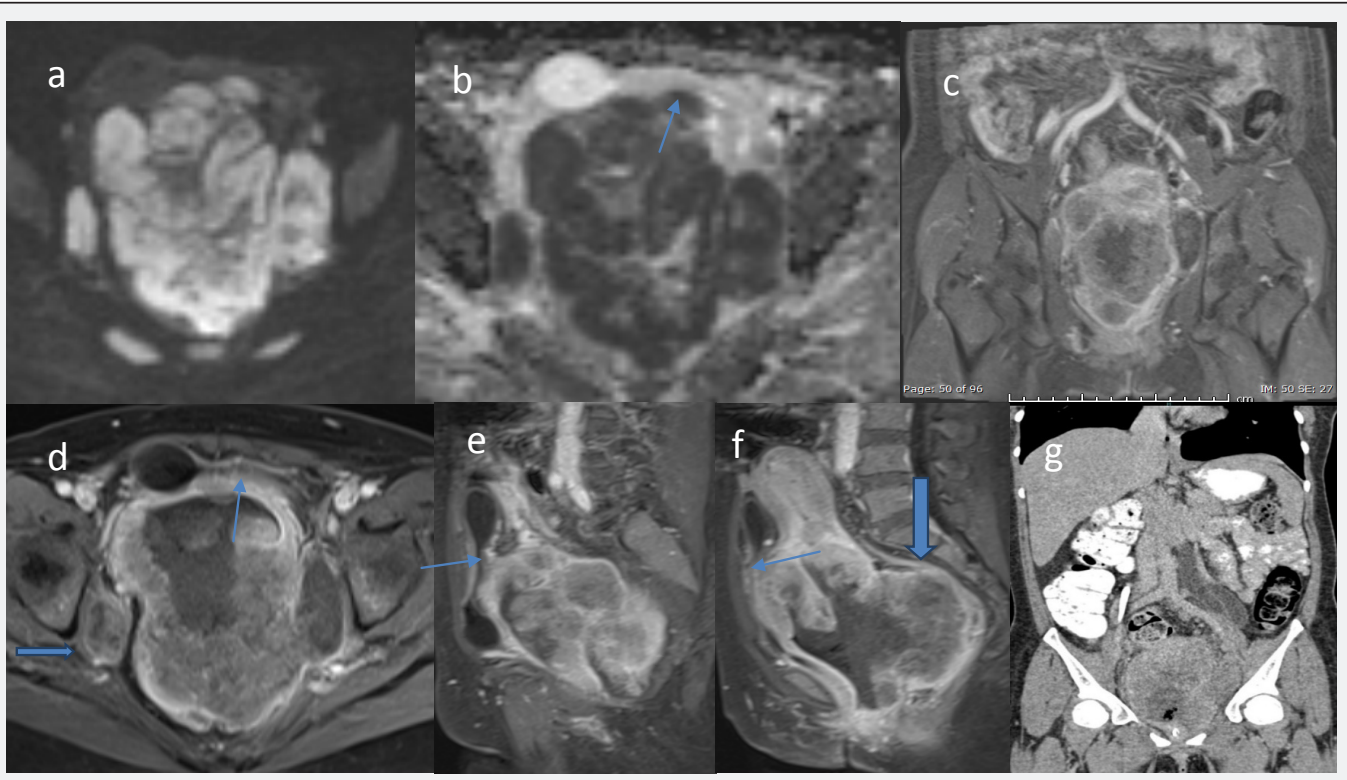

Figure 3: Large mass and enlarge lymph nodes showing remarkable diffusion restriction (image a) with dark signal in corresponding ADC (image b). T1 weighted sequence showing isointense heterogeneous mass (images not shown) Post-contrast exam reveals heterogeneous enhancement with irregular thick wall of urinary bladder showing enhancement (thin arrow in image d,e \&f). UB catheter noted. Irregular wall also noted in ADC (Thin arrow in b) Re-demonstration of enlarged bilateral iliac lymph nodes showing heterogeneous similar postcontrast enhancement (Transverse arrow in image d). Focal adjacent rectal wall involvement again seen (vertical arrow in image f). CT done showing no liver metastasis. Again left hydro ureter seen (image g). Suggestion of posterior urethral wall involvement by large mass (star in image f). 


\section{Cancer Therapy \& Oncology International Journal}

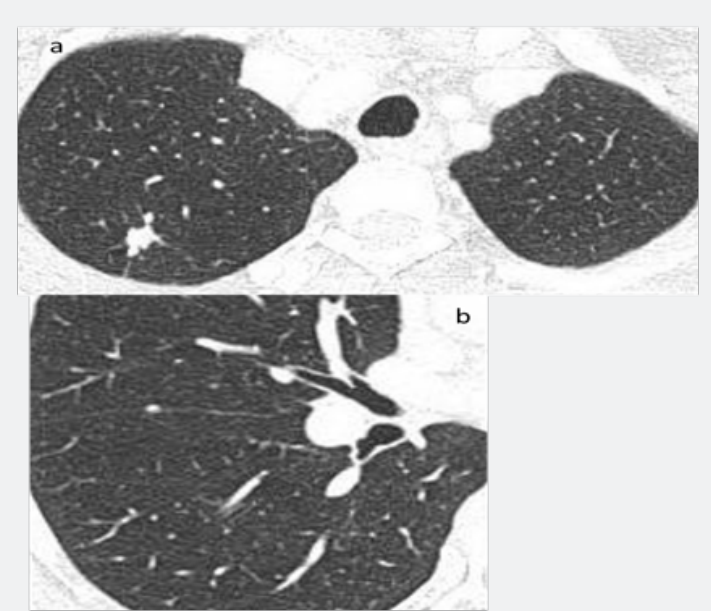

Figure 4: Two lung nodules in right lung, larger one in upper lobe and smaller one abutting major fissure.

Imaging findings: (US, MRI \& CT)

MRI: Very large lobulated heterogeneous mass seen involving the uterine cervix more on left side extending to mid to lower uterus as well as in the middle third of the vagina measures approximately $11.5 \times 8.5 \times 13.6 \mathrm{~cm}$ in maximum anterior-posterior, transverse and craniocaudal diameters. The mass showing heterogeneous iso to internal high signal areas in the 12 weighted sequences, isosignal on $\mathrm{T} 1$ weighted sequences with remarkable diffusion restriction and heterogeneous enhancement with internal non-enhancing areas. Urinary bladder is empty with catheter noted in the. Urinary bladder is compressed and starched anteriorly by large mass with focal area demonstrated large loss of fat plane by the large mass represent urinary bladder as well as thick edematous wall invasion. Suggestion of posterior urethral wall involvement by large mass. Mid to lower rectum is compressed and displaced on the right side with loss of fat plane representing a rectal involvement. Multiple enlarged bilateral pelvic as well as pre sacral lymph nodes, the largest one on left side measures approximately 35 x $55 \mathrm{~mm}$.

The lymph node demonstrated restricted diffusion and heterogeneous enhancement. In $\mathrm{T} 2$ weighted coronal and sagittal sequence demonstrated left hydro nephrosis with the dilated tortuous left ureter up to S1 level and most distal ureter is not visualized likely involved by the large mass. No right hydro nephrosis or right usual hydro ureter in MRI. The uterus appears subseptated with remarkable widening of junctional zone representing diffuse adenomyosis, more on left side showing some tiny areas of high signal in T1. Left ovary is not well visualized. Right ovary appears unremarkable. Minimal ascites in pelvic cavity. IMPRESSION: Large heterogeneous cervical mass with involvement of the lower uterus, mid third of the vagina as well as likely urinary bladder, left ureter and adjacent rectal involvement and worrisome involvement of posterior urethral wall as well as multiple enlarged lymph nodes representing cervical malignancy with FIGO stage IV a, N1.

\section{References}

1. Viviane Nicolet, Louis Carignan, France Bourdon, Odile Prosmanne (2000) MR Imaging of Cervical Carcinoma: A Practical Staging Approach. 20(6): 1539-1549.

2. Lopes Dias J, Cunha TM, Gomes FV, Callé C, Félix A (2015) Neuroendocrine tumours of the female genital tract: a case-based imaging review with pathological correlation. Insights Imaging 6(1): 43-52.

3. Harpreet K Pannu, Frank M Corl, Elliot K Fishman (2001) CT Evaluation of Cervical Cancer: Spectrum of Disease. 21(5): 1155-1168.

4. Mangal Mahajan, Rajesh Kuber, KR Chaudhari, Prashant Chaudhari, Pravin Ghadage, et al. (2013) MR imaging of carcinoma cervix, genitourinary and obstetric radiology. 23(3): 247-252.

5. Harmeet Kaur, Paul M Silverman, Revathy B Iyer, Claire F Verschraegen, Patricia J Eifel, et al. (2003) Show less, Diagnosis, Staging, and Surveillance of Cervical Carcinoma. AJR 180(6).

6. H Hricak, KK Yu (1996) Radiology in invasive cervical cancer. AJR 167(5): 1101-1108. 


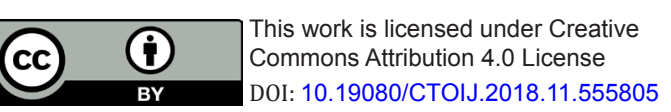

Your next submission with Juniper Publishers will reach you the below assets

- Quality Editorial service

- Swift Peer Review

- Reprints availability

- E-prints Service

- Manuscript Podcast for convenient understanding

- Global attainment for your research

- Manuscript accessibility in different formats ( Pdf, E-pub, Full Text, Audio)

- Unceasing customer service

Track the below URL for one-step submission https://juniperpublishers.com/online-submission.php 